\title{
Clinical outcomes of self-expandable metallic stents in palliation of malignant anastomotic strictures: a single center experience
}

\author{
Dario Raimondo ${ }^{1}$, Emanuele Sinagra ${ }^{1,2,3}$, Tiziana Facella ${ }^{4}$, Francesca Rossi ${ }^{1}$, Marco Messina ${ }^{5}$, Massimiliano Spada ${ }^{5}$ \\ Guido Martorana ${ }^{4}$, Pier Enrico Marchesa ${ }^{4}$, Rosario Squatrito ${ }^{6}$, Giovanni Tomasello ${ }^{3,7}$, Attilio Ignazio Lo Monte ${ }^{7}$, \\ Giancarlo Pompei ${ }^{8}$, Gaetano Cristian Morreale ${ }^{9}$, Georgios Amvrosiadis ${ }^{9}$, Marco Ciofalo $^{10}$, Ennio La Rocca ${ }^{11,6}$ \\ ${ }^{1}$ Gastroenterology and Endoscopy Unit, Fondazione Istituto San Raffaele-G.Giglio, Contrada Pietra Pollastra Pisciotto, 90015 \\ Cefalù, Italy \\ ${ }^{2} \mathrm{PhD}$ course in Surgical Biotechnology and Regenerative Medicine, University of Palermo, Italy \\ ${ }^{3}$ Euro-Mediterranean Institute of Science and Technology (IEMEST), Palermo, Italy \\ ${ }^{4}$ Surgery Unit, Fondazione Istituto San Raffaele-G.Giglio, Contrada Pietra Pollastra Pisciotto, 90015 Cefalù, Italy \\ ${ }^{5}$ Oncology Unit, Fondazione Istituto San Raffaele-G. Giglio, Contrada Pietra Pollastra Pisciotto, 90015 Cefalù, Italy \\ ${ }^{6}$ Internal Medicine Unit, Fondazione Istituto San Raffaele-G.Giglio, Contrada Pietra Pollastra Pisciotto, 90015 Cefalù, Italy \\ ${ }^{7}$ Department of Surgical and Oncological Disciplines, School of Medicine, University of Palermo, Italy \\ ${ }^{8}$ Pathology Unit, Fondazione Istituto San Raffaele-G.Giglio, Contrada Pietra Pollastra Pisciotto, 90015 Cefalù, Italy \\ ${ }^{9}$ Gastroenterology Unit, Ospedali Riuniti Villa Sofia - V. Cervello, Via Trabucco 180, 90146 Palermo, Italy \\ ${ }^{10}$ School of Medicine, University of Palermo, Italy \\ ${ }^{11}$ Unità Operativa di Medicina interna e trapiantologia, Ospedale San Raffaele, via Olgettina 60, Milano, Italy
}

Correspondence: Emanuele Sinagra

E-mail: emanuelesinagra83@googlemail.com

Received: January 07, 2015

Published online: February 22, 2015

Background: Self-expandable metallic stents (SEMS) are employed as the preferred nonsurgical palliative treatment for gastric outlet obstruction due to malignancies. Metallic stents are often employed to treat malignant anastomotic obstructions after surgical interventions as esophagojejunostomy, gastrojejunostomy and esophagogastrojejunostomy. Methods: This case series reports prospectively the clinical outcomes of SEMS in the palliative care of malignant anastomotic strictures caused by the recurrence of gastric cancer following gastric surgery as oncological curative treatment, in a series of nine consecutive patients, treated between January 2009 and December 2012 in our center. Results: Nine patients ( $\mathrm{M}: \mathrm{F}=8: 1)$ were enrolled in the study. The operation was a total gastrectomy with esophagogastrojejunostomy ( $\mathrm{n}=4)$, subtotal gastrectomy with Billroth-II reconstruction ( $\mathrm{n}=3$ ), and subtotal gastrectomy with esophagogastrostomy $(n=2)$.The technical success rate was $88.9 \%$, and the clinical success rates was $88,9 \%$. The reobstruction of the stent, due to the ingrowth of the tumor, occurred in 1 patient $(11,1 \%)$ within 1 month after stent placement. The migration of the stent occurred after the placement of a covered stent in 1 patient who underwent a subtotal gastrectomy (with Billroth-II reconstruction). A case of partial stent dislodgement was easily treated with the placement of a second stent. The median survival period was 180 days (range, 30-240 days) and the median stent patency was 45 days (range, 30-90 days). Conclusions: Although the number of the patients treated with SEMS results, in this series, almost small to certainly judge the safety and feasibility of SEMS, we believe that the endoscopic insertion of SEMS seems to be a safe, easily feasible, and effective treatment in the palliative care of malignant anastomotic strictures caused by the recurrence of gastric cancer following gastric surgery. The technical and clinical success, and the onset of complications of this procedure are influenced by several factors, such as the type of anastomosis, the technical features of the stent, and the extent of the underlying tumor. 


\section{Keywords: SEMS; gastrectomy; Gastric cancer; anastomotic stricture}

To cite this article: Dario Raimondo, et al. Clinical outcomes of self-expandable metallic stents in palliation of malignant anastomotic strictures: a single center experience. Abdomen 2015; 2: e511. doi: 10.14800/Abdomen.511.

\section{Introduction}

Self-expandable metallic stents (SEMS) are used as the preferred nonsurgical palliative treatment for malignant gastric outlet obstruction ${ }^{[1]}$. Metallic stents are often employed to treat malignant anastomotic obstructions after surgical interventions as esophagojejunostomy, gastrojejunostomy and esophagogastrojejunostomy. High mortality and morbidity following palliative surgery is observed in patients with advanced disease, poor general conditions, prolonged hospitalization, and digestive tract dysfunctions, such as delayed gastric emptying or bilious vomiting ${ }^{[2]}$.

Few data are available about the use of SEMS for the nonsurgical palliative treatment for recurrent malignant gastric outlet obstruction ${ }^{[3-11]}$. To our knowledge, few studies focused on endoscopic placement of SEMS in the recurrence of anastomotic strictures ${ }^{[11-15]}$. In this setting, the clinical outcomes and complications might differ according to the surgical technique because of the different anastomotic angle or different anatomical alterations during surgery.

Aim of our study is to report prospectively the clinical outcomes of SEMS, in the palliative care of anastomotic strictures, due to the recurrence of gastric cancer following gastric surgery as oncological curative treatment, in a series of nine consecutive patients.

\section{Methods}

Nine consecutive patients $(\mathrm{M}: \mathrm{F}=8: 1$, median age 76 years, range $48-85$ years), who presented a post-operative anastomotic strictures, due to the recurrence of gastric cancer and underwent endoscopic SEMS placement from January 2009 to december 2012, were included in the study. All patients presented with a symptomatic obstruction, as confirmed by a median gastric outlet obstruction score (GOOS) $>1$.

The recurrence of gastric cancer, cause of the obstruction, was confirmed, in all patients, by experienced pathologists. No patient was a surgical candidate, due to the presence of metastatic disease or due to medical comorbidities.

The exclusion criteria were the following: (a) asymptomatic or mildly symptomatic patients; (b) patency of the malignant anastomotic stricture, with regard to an adult endoscope; (c) clinical evidence of peritonitis. Before the endoscopic procedure, an abdominal computed tomography (CT) scan was performed, in order to exclude multiple strictures.

The type of surgery performed was a total gastrectomy with esophagogastrojejunostomy in 4 patients, subtotal gastrectomy with Billroth-II reconstruction in 3 patients, and subtotal gastrectomy with esophagogatrostomy in 2 patients. The margins of the proximal and distal section were, after surgical intervention, histologically free from tumor invasion [12].

NITI-S stents (Taewoong, Seoul, Korea, $n=2$ ), WallFlex duodenal stents (Boston Scientific, Boston, Mass, USA, n=3) and Evolution esophageal partially covered stents (Cook Medical Endoscopy, Bloomington, Ind, USA, n=4) were used. The degree, lenght and location of the stenosis were evaluated using an endoscopic procedure or contrast media radiographic study, prior to stent placement. Two out of nine stents were fully covered, five out of nine were uncovered, and two out of nine were partially covered.

The Niti-S stent (Taewoong Medical, Seoul, Korea) has a double layer configuration over its entire length, consisting of an inner polyurethane layer over its complete length and an outer uncovered nitinol wire. The stent flares to $26 \mathrm{~mm}$ at its proximal and distal ends with a body diameter of $18 \mathrm{~mm}$. It is available in three lengths: 9, 12, and $15 \mathrm{~cm}$. The stent is delivered in a compressed form inside an introducer sheath [16]

The WallFlex duodenal stent (Boston Scientific Co., Natick, Mass., USA) is an uncovered SEMS composed of nitinol. It has a flare at the proximal end to minimize the risk of migration and looped ends to reduce the risk of tissue injury. The diameter is $22 \mathrm{~mm}$ at the body and $27 \mathrm{~mm}$ at the flared proximal end. This stent is available in 60-, 90-, or 120-mm lengths ${ }^{[17]}$.

Evolution (Cook, Bloomington, Ind, USA) is available as a partially or fully covered SEMS. The stent is encased with silicone on its exterior and interior surfaces to prevent tumor in growth. A unique feature of Evolution delivery system is that it enables a controlled release and recapturability feature with a "point of no return" indicator. With each squeeze of the stent system's trigger-based introducer, a proportional length of the stent is deployed or recaptured ${ }^{[18]}$. 
Table 1. Patients' features

\begin{tabular}{|c|c|}
\hline Age (median, range) & $76,48-85$ \\
\hline Male/Female ratio & $8: 1$ \\
\hline $\begin{array}{l}\text { Prior surgery (n): } \\
\text { - total gastrectomy with } \\
\text { esophagogastrojejunostomy } \\
\text { - subtotal gastrectomy with Billroth-II } \\
\text { reconstruction } \\
\text { - subtotal gastrectomy with } \\
\text { esophagogatrostomy }\end{array}$ & $\begin{array}{l}4 \\
3 \\
2\end{array}$ \\
\hline Chemotherapy after stent placement (n) & 2 \\
\hline Follow up loss (n) & 0 \\
\hline 30-days mortality & $0,00 \%$ \\
\hline Survival (in days, median, range) & $180(30-240)$ \\
\hline Stent patency (in days, median, range) & $45(30-90)$ \\
\hline
\end{tabular}

The patients usually resumed a water or a liquid diet $24 \mathrm{~h}$ after stent placement, then they started a soft or solid diet after the follow up X-ray showed full extension of the stent. After the placement of the stent, a chemotherapy (based on the judgement of the oncologist) was administered when the oral intake improved and the Eastern Cooperative Oncology Group performance status was $\leq 2$ (graded as follows: $0=$ normal activity, $1=$ symptoms but ambulatory, $2=$ in bed less than $50 \%$ of time, $3=$ in bed more than $50 \%$ of time, and 4 = totally bedridden). After stent placement, palliative chemotherapy was performed in two patients $(22,2 \%)^{[9]}$.

The outcome of the stent was evaluated according to: (1) technical success and clinical success; (2) complications; (3) stent patency.

The technical success was defined as the successful placement of a stent in the correct location and the confirmation of its patency using both the endoscopy and the fluoroscopy with oral contrast. The clinical success was defined as the improvement or the resolution of the obstructive symptoms and oral intake 1 to $3 \mathrm{~d}$ after the placement of the stent. The degree of oral intake was assessed using the Gastric Outlet Obstruction Scoring System as follows: $0=$ no oral intake; 1 = exclusively liquid diet; 2 = exclusively soft solids diet; 3 = full diet possible.

A primary stent dysfunction was defined as the impossibility to resume an oral intake after stent placement.

The stent patency time was defined as the duration between the initial stent insertion and the recurrence of obstructive symptoms due to the occlusion of the stent ${ }^{[12]}$.

All patients were followed up to estabilish their clinical outcomes until they died or the stent did not function, such as by dislodgement or occlusion by tumor in growth or overgrowth. The data were reported from the hospital records. The status of oral food intake was monitored at 1 month intervals on an outpatient basis. A follow-up barium study or endoscopy was performed only if obstructive symptoms recurred in order to determine stent occlusion or dislodgement ${ }^{[12]}$.

\section{Results}

\section{-Technical and clinical success}

Endoscopic stent placement was technically successful in eight out of nine patients (88, 9\%). Clinical success (GOOS: 3) was achieved in eight out of nine patients (88, $9 \%)$

\section{-Complications}

There was no procedure-related mortality. Only in one patient who underwent a distal gastrectomy (with Billroth-reconstruction), the uncovered stent did not expand completely and was compressed by the tumor mass until 5 days after stent insertion. The symptoms were not improved. However, he refused further treatments and was treated with supportive care.

The recurrence of symptoms of an obstruction was observed in 2 patient $(22,2 \%)$ as a result of tumor ingrowth $(\mathrm{n}=2)$ within 1 month after stenting. The reobstruction rate (1/4 vs 1/5) of a covered (fully and partially) stent and uncovered stent, and stent patency duration [45 days (range, 30-90) for the covered stent vs 45 days (range, 30-90) for the uncovered stent] were similar.

Tumor overgrowth did not occurred (0\%). Tumor ingrowth occurred in two patients (22, $2 \%)$ who underwent a 
http://www.smartscitech.com/index.php/Abdomen

Table 2.Complications associated with stent placement

\begin{tabular}{|l|l|l|l|l|l|}
\hline Patient & Complication & $\begin{array}{l}\text { Type of } \\
\text { surgery }\end{array}$ & Type of stent & $\begin{array}{l}\text { Days after } \\
\text { stenting }\end{array}$ & Treatment \\
\hline 1 & $\begin{array}{l}\text { Tumor } \\
\text { ingrowth }\end{array}$ & $\begin{array}{l}\text { Billroth II } \\
\text { subtotal } \\
\text { gastrectomy }\end{array}$ & Uncovered & 30 & $\begin{array}{l}\text { Refusal of } \\
\text { treatment }\end{array}$ \\
\hline 2 & $\begin{array}{l}\text { Tumor } \\
\text { ingrowth }\end{array}$ & $\begin{array}{l}\text { Total } \\
\text { gastrectomy }\end{array}$ & $\begin{array}{l}\text { Partially } \\
\text { covered }\end{array}$ & 30 & $\begin{array}{l}\text { Refusal of } \\
\text { treatment }\end{array}$ \\
\hline 3 & $\begin{array}{l}\text { Stent migration } \\
\text { (complete) }\end{array}$ & $\begin{array}{l}\text { Billroth II } \\
\text { subtotal } \\
\text { gastrectomy }\end{array}$ & $\begin{array}{l}\text { Partially } \\
\text { covered }\end{array}$ & 15 & $\begin{array}{l}\text { Elective } \\
\text { surgery }\end{array}$ \\
\hline 4 & $\begin{array}{l}\text { Stent migration } \\
\text { (partial) }\end{array}$ & $\begin{array}{l}\text { Total } \\
\text { gastrectomy }\end{array}$ & Full covered & 15 & $\begin{array}{l}\text { Second stent } \\
\text { placement }\end{array}$ \\
\hline
\end{tabular}

subtotal gastrectomy with Billroth-II reconstruction, in whom an uncovered stent was placed and who underwent to esophago-jejunostomy, in whom a partially covered stent was placed, respectively. Interestingly, tumor in growth occurred in patients with signet ring cell gastric adenocarcinoma. The patients were successively treated conservatively, because of the refusal of further invasive treatments.

Partial stent dislodgement to the more distal side of the efferent loop occurred in one patient $(11,1 \%)$, two days after stent insertion. The patient was treated by placing a second stent into the previous stent, with subsequent clinical improvement.

Complete stent dislodgement occurred at 15 days in one patient with esophago-gastrostomy (11, 1\%). The migrated stent was detected into the stomach. He presented with abdominal pain, and was treated with elective esophagojejunostomy.

Further complications after SEMS insertion, as fever, aspiration pneumonia, bleeding and perforation were not observed.

\section{-Survival}

None of the patients was lost during the follow-up period, but all the nine patients died. The median survival period was 180 days (range, 30-240 days) and the median stent patency was 45 days (range, 30-90 days).

\section{Discussion}

SEMS placement has emerged as a nonsurgical palliative treatment and has shown promising results in the setting of the palliative care ${ }^{[19,20]}$. A SEMS has several clinical advantages, compared with surgery, such as rapid resumption of oral intake, shorter hospital stay and rapid improvement in the quality of life in gastric obstruction due to recurrent gastric cancer $^{[21,22]}$.

In this series, the technical success rate was 88, $9 \%$, which is comparable to those with a primary malignant gastric outlet obstruction (83\%-100\%) ${ }^{[20]}$. The dietary intake improved in $88,9 \%$ of patients after stent placement, which is comparable to the clinical success rate of SEMS insertion in a malignant gastric outlet obstruction (75\%-85\%) ${ }^{[21]}$. The improvement in symptoms after SEMS insertion in the anastomotic stricture caused by the recurrence of gastric cancer was reported to be $80 \%-90 \%$ (3-8). In our series, a CT scan performed prior to the stent placement excluded concealed obstructions. In the series reported by Cho and coworkers ${ }^{[12]}$, five out twenty patients whose symptoms did not improve had another single stricture at the small intestine or colon, or ileus by peritoneal dissemination. For this reason, the authors suggested that a study of the distal bowel loop using a CT scan or barium study before stent placement might be useful in order to exclude a concealed obstruction.

A further occlusion of the stent, due to tumor in growth, occurred in two patients (22, 2\%) within 1 month after stent placement. A previous study reported that early restenosis within 1 month tended to occur more frequently in postoperative anastomosis than a gastric outlet obstruction caused by primary cancer (4/6 vs $2 / 6, \mathrm{P}<0.01)^{[23]}$. The covered stents had the merit of less frequent reobstruction by tumor ingrowth ${ }^{[24]}$. However, in this study, the reobstruction rate and stent patency duration of covered stents and uncovered stents were similar. The incidence of stent reobstruction in recurrent anastomotic stricture after gastric surgery was reported to be $0 \%-17 \%{ }^{[3-8]}$. Most studies used covered stents. In two studies using uncovered stents, Lee and coworkers ${ }^{[6]}$ reported that one out of 4 patients had tumor ingrowth, and Song and coworkers ${ }^{[7]}$ reported a 50\% stent reobstruction rate within 2 weeks of stent placement. A prospective, randomized, comparative study to determine which stent is favorable in this situation will be needed. 
http://www.smartscitech.com/index.php/Abdomen

One case of stent dislodgement $(11,1 \%)$ was encountered in patients who underwent a subtotal gastrectomy with Billroth-II reconstruction and had a covered stent inserted. A complete stent migration occurred at 15 days in one patient with esophago-gastrostomy $(11,1 \%)$. The migrated stent was detected into the stomach. He presented with abdominal pain, and was treated with elective esophagojejunostomy. The incidence of stent dislodgement was reported to be $0 \%-16 \%$ in studies using a covered stent in an anastomotic stricture in various types of gastric cancer surgery ${ }^{[3-8]}$. The surgical technique could influence the percentage of dislodgement. The relatively acute angle between anastomosis and the efferent loop in gastrojejunostomy compared with the relatively obtuse angle in esophagojejunostomy or gastroduodenostomy, the radial force of the stent in the angulated loop, or the use of a covered stent may influence stent migration ${ }^{[12]}$.

In this study, the 30-day mortality was $0 \%$. The median survival period was 180 days (range, 30-240 days) and the median stent patency was 45 days (range, 30-90 days). Since the median survival in an anastomotic obstruction is similar to that in a primary malignant gastric outlet obstruction, strategies to prolong stent patency and avoid the need for further intervention are useful in patients with malignant recurrence, particularly those with a good performance status or who are expected to have a prolonged survival.

In the study performed by Cho and coworkers, the authors showed that the technical and clinical success of SEMS placement for anastomotic strictures due to the recurrence of gastric cancer were $100 \%$ and $70 \%$, respectively. In this study, clinical failure was due to small bowel or colon stricture in addition to anastomotic stricture. Stent migration (15\%) was reported in patients who underwent subtotal gastrectomy with Billroth-II reconstruction and had a covered stent placed ${ }^{[12]}$.

Song and coworkers ${ }^{[13]}$ placed SEMS in 39 patients with malignant anastomotic obstructions after gastrojejunostomy and reported their results. In their series, stent placement was technically achieved in all patients, and 35 patients (90\%) obtained relief from their obstructive symptoms. However, aspiration pneumonia, stent migration, and reobstruction occurred in 2, 4, and 2 patients, respectively, with a total complication rate of $23.1 \%$. Kim and coworkers ${ }^{[14]}$ also reported the results for 39 postgastrectomy patients who underwent SEMS placement. The technical success rate was $92 \%$ and the total complication rate was $44 \%$. In the series of Kim and coworkers [14], 2 patients suffered from stent-associated perforation. On the basis of previous studies, it was supposed that SEMS placement is more risky in postgastrectomy patients than in patients with unresectable primary gastric cancers, although the treatment is technically feasible ${ }^{[25]}$

Our study presents some limitations. First, the small number of patients and the use of several types of SEMS could affect the representativeness of the studied population. Second, the fact that no patient was a candidate for surgery may creates a selection bias. However, in this study we represent our personal experience in this subset of patients, comparing it with the data available from the scientific literature.

\section{Conclusions}

The endoscopic placement of a SEMS seems to be a safe, easily feasible, and effective treatment in the palliative care of malignant anastomotic strictures caused by the recurrence of gastric cancer following gastric surgery. The technical and clinical success, and the onset of complications of this procedure are influenced by several factors, such as the type of anastomosis, the technical features of the stent, and the extent of the underlying tumor (which can influence, for example, the presence of concealed obstructions).

\section{Conflict of interests: none declared for all the authors}

\section{Acknowledgement: none}

\section{References}

1. Dormann A, Meisner S, Verin N, Wenk Lang A. Selfexpanding metal stents for gastroduodenal malignancies: systematic review of their clinical effectiveness. Endoscopy 2004; 36: 543-550

2. Maosheng D, Otsuka T, Ohuchida J, Indue K, Yokohata K, Yamaguchi $\mathrm{K}$, et al. Surgical bypass versus metallic stent for unresectable pancreatic cancer. J Hepatobiliary Pancreat Surg 2001;8:367-373

3. Cheung HY, Chung SC. Covered metal stent for tumor obstruction of efferent loop recurrence after gastrectomy. Surg Endosc 1997; 11: 936-938

4. Jeong JY, Kim YJ, Han JK, Lee JM, Lee KH, Choi BI, et al. Palliation of anastomotic obstructions in recurrent gastric carcinoma with the use of covered metallic stents: clinical results in 25 patients. Surgery 2004; 135: 171-177

5. Jeong JY, Han JK, Kim AY, Lee KH, Lee JY, Kang JW, et al. Fluoroscopically guided placement of a covered self-expandable metallic stent for malignant antroduodenal obstructions: preliminary results in 18 patients. AJR Am J Roentgenol 2002; 178: $847-852$

6. Lee JM, Han YM, Kim CS, Lee SY, Lee ST, Yang DH. Fluoroscopic-guided covered metallic stent placement for gastric outlet obstruction and post-operative gastroenterostomy anastomotic stricture. Clin Radiol 2001; 56: 560-567

7. Song HY, Kim TH, Choi EK, Kim JH, Kim KR, Shin JH, et al. Metallic stent placement in patients with recurrent cancer after 
http://www.smartscitech.com/index.php/Abdomen

gastrojejunostomy. J Vasc Interv Radiol 2007; 18: 1538-1546

8. Yang ZQ, Song HY, Kim JH, Shin JH, Kim TW, Yook JH, et al. Covered stent placement in patients with recurrent cancer after a Billroth I reconstruction. J Vasc Interv Radiol 2007; 18: 1533-1537

9. Wayman J, Bliss R, Richardson DL, Griffin SM. Selfexpanding metal stents in the palliation of small bowel stenosis secondary to recurrent gastric cancer. Gastrointest Endosc 1998; 47: 286-290

10. Patton JT, Carter R. Endoscopic stenting for recurrent malignant gastric outlet obstruction. Br J Surg 1997; 84: 865-866

11. Song GA, Kang DH, Kim TO, Heo J, Kim GH, Cho M, et al. Endoscopic stenting in patients with recurrent malignant obstruction after gastric surgery: uncovered versus simultaneously deployed uncovered and covered (double) selfexpandable metal stents. Gastrointest Endosc 2007; 65: 782-787

12. Cho Yk, Kim SW, Nam KW, Chang JH, Park JM, Jeong JJ, et al. Clinical outcomes of self-expandable metal stents in palliation of malignant anastomotic strictures caused by recurrent gastric cancer. World J Gastroenterol 2009 July 28; 15(28): 3523-3527

13. Song HY, Kim TH, Choi EK, Kim JH, Kim KR, Shin JH, et al. Metallic stent placement in patients with recurrent cancer after gastrojejunostomy. J Vasc Interv Radiol 2007;18:1538-1546.

14. Kim J, Choi IJ, Kim CG, Lee JY, Cho SJ, Park SR, et al. Self-expandable metallic stent placement for malignant obstruction in patients with locally recurrent gastric cancer. Surgical Endoscopy 2011;25:1505-1513.

15. Dormann A, Meisner S, Verin N, Wenk Lang A: Self-expanding metal stents for gastroduodenal malignancies: systematic review of their clinical effectiveness. Endoscopy 2004;36:543-550.

16. Verschuur E, Repici A, Kuipers EJ, Steyerberg EW, Siersema PD. New Design Esophageal Stents for the Palliation of Dysphagia From Esophageal or Gastric Cardia Cancer: A Randomized TrialNew Esophageal Stent Designs for Malignant Dysphagia. The American Journal of Gastroenterology 103, 304-312
17. Sasaki T, Isayama H, Maetani I, Nakai Y, Kogure H, Kawakubo $\mathrm{K}$, et al. Japanese multicenter estimation of WallFlex duodenal stent for unresectable malignant gastric outlet obstruction. Dig Endosc. 2013 Jan;25(1):1-6.

18. Martinez JC, Puc MM, Quiros RM. Esophageal Stenting in the Setting of Malignancy. ISRN Gastroenterology 2011, Article ID 719575, 9 pages.

19. Kim JH, Song HY, Shin JH, Choi E, Kim TW, Jung HY, et al. Metallic stent placement in the palliative treatment of malignant gastroduodenal obstructions: prospective evaluation of results and factors influencing outcome in 213 patients. Gastrointestinal Endoscopy 2007;66:256-264.

20. Iwanaga $T$, Koyama $H$, Furukawa $H$, Taniguchi $H$, Wada A, Tateishi R. Mechanisms of late recurrence after radical surgery for gastric carcinoma. Am J Surg 1978; 135: 637-640

21. Jeurnink SM, van Eijck CH, Steyerberg EW, Kuipers EJ, Siersema PD. Stent versus gastrojejunostomy for the palliation of gastric outlet obstruction: a systematic review. BMC Gastroenterol 2007; 7: 18

22. Adler DG, Merwat SN. Endoscopic approaches for palliation of luminal gastrointestinal obstruction. Gastroenterol Clin North Am 2006; 35: 65-82

23. Kim GH, Kang DH, Lee DH, Heo J, Song GA, Cho M, et al. Which types of stent, uncovered or covered, should be used in gastric outlet obstructions? Scand J Gastroenterol 2004; 39: 1010-1014

24. Jung GS, Song HY, Kang SG, Huh JD, Park SJ, Koo JY, et al. Malignant gastroduodenal obstructions: treatment by means of a covered expandable metallic stent-initial experience. Radiology 2000; 216: 758-763

25. Kakuta T, Yajima K, Kayama S, Tsuno Y, Saito K, Ishikawa T, et al. WallFlex Duodenal Stent Placement in a Gastric Cancer Patient with a Malignant Stenosis of a Roux-en-Y Gastrojejunostomy following Distal Gastrectomy. Case Rep Oncol 2012;5:554-560 